\title{
Body weights of the Cape hare Lepus capensis in the northern China
}

\begin{abstract}
Xin LU
Lu X. 2000. Body weights of the Cape hare Lepus capensis in the northern China. Acta Theriologica 45: 271-280.

This paper analyzed body weights of the Cape hare Lepus capensis Linnaeus, 1758 in northern China during 1990-1993. Body weight of the hares increased faster in the first five months of life. The juveniles with the same eye lens weight weighed less in spring-summer than in autumn, in the southern region than in the northern. The overwintering females increased weight with reproduction, the older of which gained more. In autumn-winter, body weights of adult females and males in the whole study region were $2.29 \pm 0.05$ and $2.11 \pm 0.06 \mathrm{~kg}$ respectively. Body weight of the overwintering hares varied seasonally. At the beginning of the breeding season female was the lightest while male the heaviest, and then female became heavier and male lighter. Regardless of age, area and season, females were usually heavier than males.

College of Life Sciences, University of Wuhan, Wuhan 430072, P. R. China, e-mail: luxinwh@public.wh.hb.cn

Key words: Lepus capensis, body weight, northern China
\end{abstract}

\section{Introduction}

The Cape hare Lepus capensis Linnaeus, 1758, with widest distribution range among all the hare species in the world (Chapman and Flux 1990), occurs over most of northern China and is one of the most important game animals in the country. Little is known about its biology and ecology (but see Agnew and Flux 1970, Flux and Jarvis 1970, Stewart 1971, Lu et al. 1994, 1995, Lu 1995). This paper is concerned with the body weight of the hare in northern China.

\section{Material and methods}

Of 2076 hares examined in this study, 1863 were shot from 12 sites $\left(34^{\circ} 40^{\prime}-40^{\circ} 02^{\prime} \mathrm{N}\right.$, $110^{\circ} 10^{\prime}-113^{\circ} 26^{\prime} \mathrm{E}$, Fig. 1) of two provinces Shanxi and Shannxi in northern China in the hunting seasons (October-January) 1990-1993, and 213 from site III during the breeding season (February-September) 1991. The specimens were weighed to the nearest $0.01 \mathrm{~kg}$ and sexed by inspecting ovary or testis. If embryos were obvious, their weights were not added to the body weight of the pregnant female. In October, less than $1 \%$ of the breeding females were lactating in site I and II, and no suckling female was found in other sites. 942 hares were divided as juvenile $(<1$ year) and adult ( $>1$ year) by eye lens weight ( $\mathrm{Lu}$ et al. 1994). Eye lens weight is little affected by food conditions (Friend and Severinghaus 1967) and its growth period is over one year (Broekhuizen and Maaskamp 1979). So it 


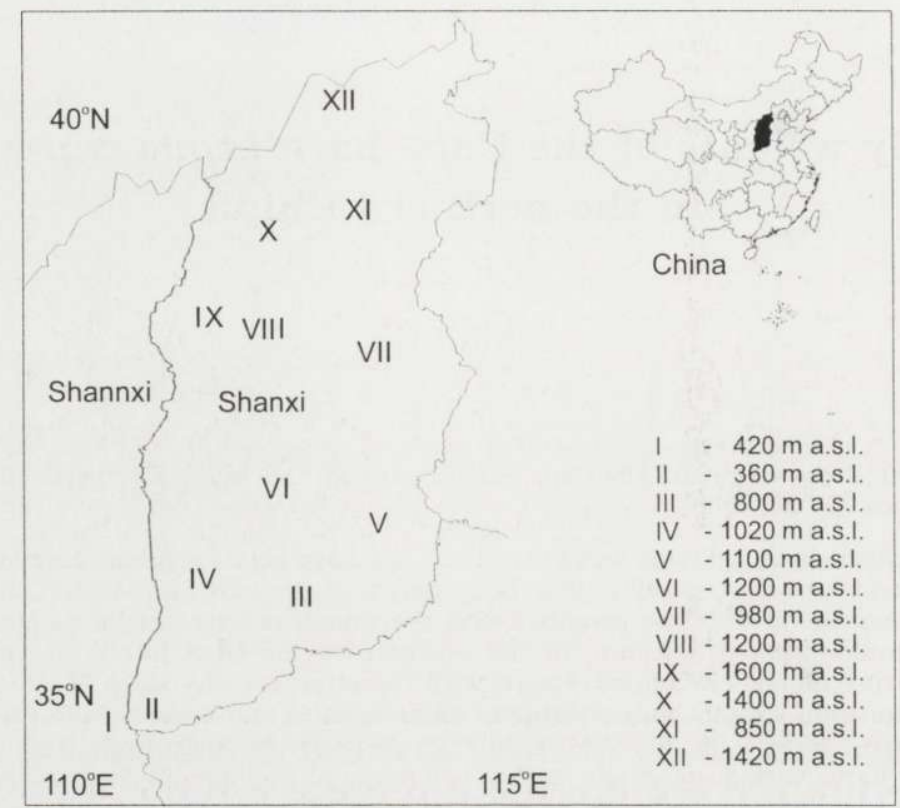

Fig. 1. A map showing the sites from which the materials were obtained. The features of those investigated sites were as follows: I - farmland in plain; II - flood plain of the Yellow river with farmland; III - mountain with scrub, woodland and farmland; IV - mountain with scrub; V - hill with scrub and farmland; VI - mountain with scrub and farmland; VII - hill with scrub and farmland; VIII loess ravine with scrub and farmland; IX - mountain covered with forest; X - sandy area with scrub; XI - flood plain with grassland and farmland; XII - hill with scrub.

was also used as a relative criterion for determining ages of juvenile. The comparison of body weights between juveniles should be made at the same age and thus ANCOVA (eye lens weights as covariant) was employed to avoid the bias caused by mixed-age specimens. Student $t$-test was used to estimate the significance of difference of mean body weights between adults, juveniles of attaining adult body weights or those without records of eye lens weight. All expressions of body weight were mean $\pm \mathrm{SE}$ and significant levels two tailed. The software STATISTICS was applied to make statistical analysis.

\section{Results}

\section{Growth of body weight of juvenile}

Most females produced their first litters in mid-February and the last in

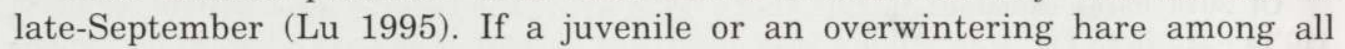
specimens from a specific month had the heaviest or the lightest eye lens, its age should be the difference between the month in which the hare was shot and that in which the hare was firstly or lastly given birth. Based on this consideration, a rough estimation to growth of eye lens weight could be made through the juvenile and overwintering specimens shot monthly in site III from January to November 1991 (Fig. 2). The growth curves of body weights of those juveniles thus could be drawn 


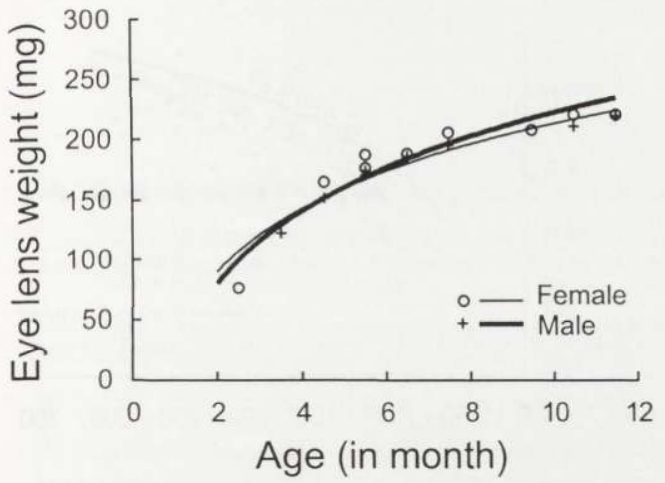

Fig. 2. Growth curves of eye lens weights of hares. Regression between eye lens weights and ages: Female: $y=12.72 x+93.30, R^{2}=0.73, n=9$, $p<0.0025$; Male: $y=10.36 x+107.55, R^{2}=0.87$, $n=8, p<0.0001$.

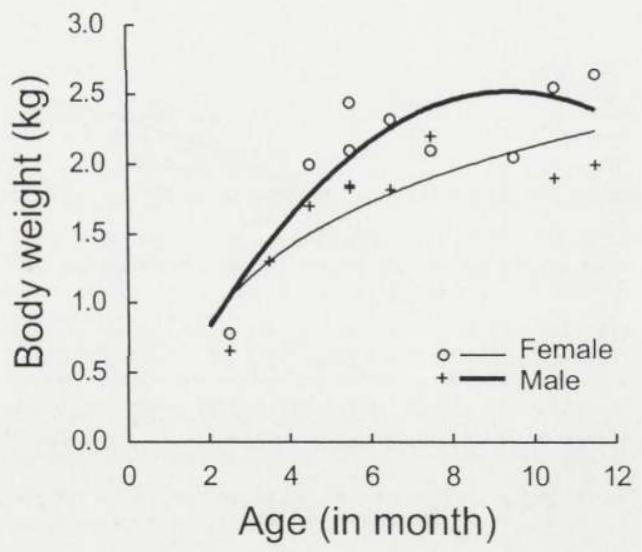

Fig. 3. Growth curves of body weights of hares.

(Fig. 3). The results showed that eye lens weights had been increasing for over one year. The maximum eye lens weights found in this study were $336.8 \mathrm{mg}$ in female and $314.0 \mathrm{mg}$ in male. While body weights had experienced a rapid growth period during the first several months of life. The relationship between body weights and eye lens weights also showed the tendency (see below). When eye lens weight was over $180 \mathrm{mg}$, ie about 6 months old, the juveniles became as heavy as adults (Table 1).

Fig. 4 revealed a striking linear correlation between body weights and eye lens weights under $180 \mathrm{mg}$ during the rapidly-growing period $(r=0.79-0.89, p<0.001)$. However, with the same eye lens weight (100-180 mg), from the regression equations, the juveniles from site III in spring-summer (May-September) weighed less 106.9-202.9 $\mathrm{g}$ in female than those in autumn (October-November) (Fig. 4a, ANCOVA, $F_{1,59}=3.90, p<0.05$ ), though some of them became heavier due to

Table 1. Comparison of body weights (in $\mathrm{kg}$ ) of hares with eye lens weights of $180-225 \mathrm{mg}$ and of those over 225 mg. $n$-sample size.

\begin{tabular}{|c|c|c|c|c|c|c|c|c|}
\hline \multirow{2}{*}{ Sites } & \multirow{2}{*}{ Time } & \multirow{2}{*}{$\begin{array}{c}\text { Eye lens } \\
\text { weight }\end{array}$} & \multicolumn{3}{|c|}{ Female } & \multicolumn{3}{|c|}{ Male } \\
\hline & & & $n$ & Mean \pm SE & $t$-test & $n$ & Mean $\pm \mathrm{SE}$ & $t$-test \\
\hline \multirow[t]{2}{*}{ II } & Oct-Nov & $180-225$ & 22 & $2.25 \pm 0.05$ & $t=0.84$ & 18 & $2.06 \pm 0.05$ & $t=0.44$ \\
\hline & & $>225$ & 4 & $2.36 \pm 0.15$ & $p>0.45$ & 3 & $2.00 \pm 0.07$ & $p>0.70$ \\
\hline \multirow[t]{2}{*}{ III } & Jan-Nov & $180-225$ & 15 & $2.25 \pm 0.06$ & $t=1.91$ & 14 & $1.92 \pm 0.04$ & $t=1.53$ \\
\hline & & $>225$ & 45 & $2.38 \pm 0.03$ & $p>0.05$ & 25 & $2.01 \pm 0.04$ & $p>0.10$ \\
\hline \multirow[t]{2}{*}{$\mathrm{X}-\mathrm{XI}$} & Oct-Nov & $180-225$ & 4 & $2.29 \pm 0.08$ & $t=0.44$ & 6 & $2.22 \pm 0.04$ & $t=0.31$ \\
\hline & & $>225$ & 4 & $2.37 \pm 0.33$ & $p>0.70$ & 4 & $2.24 \pm 0.05$ & $p>0.80$ \\
\hline
\end{tabular}



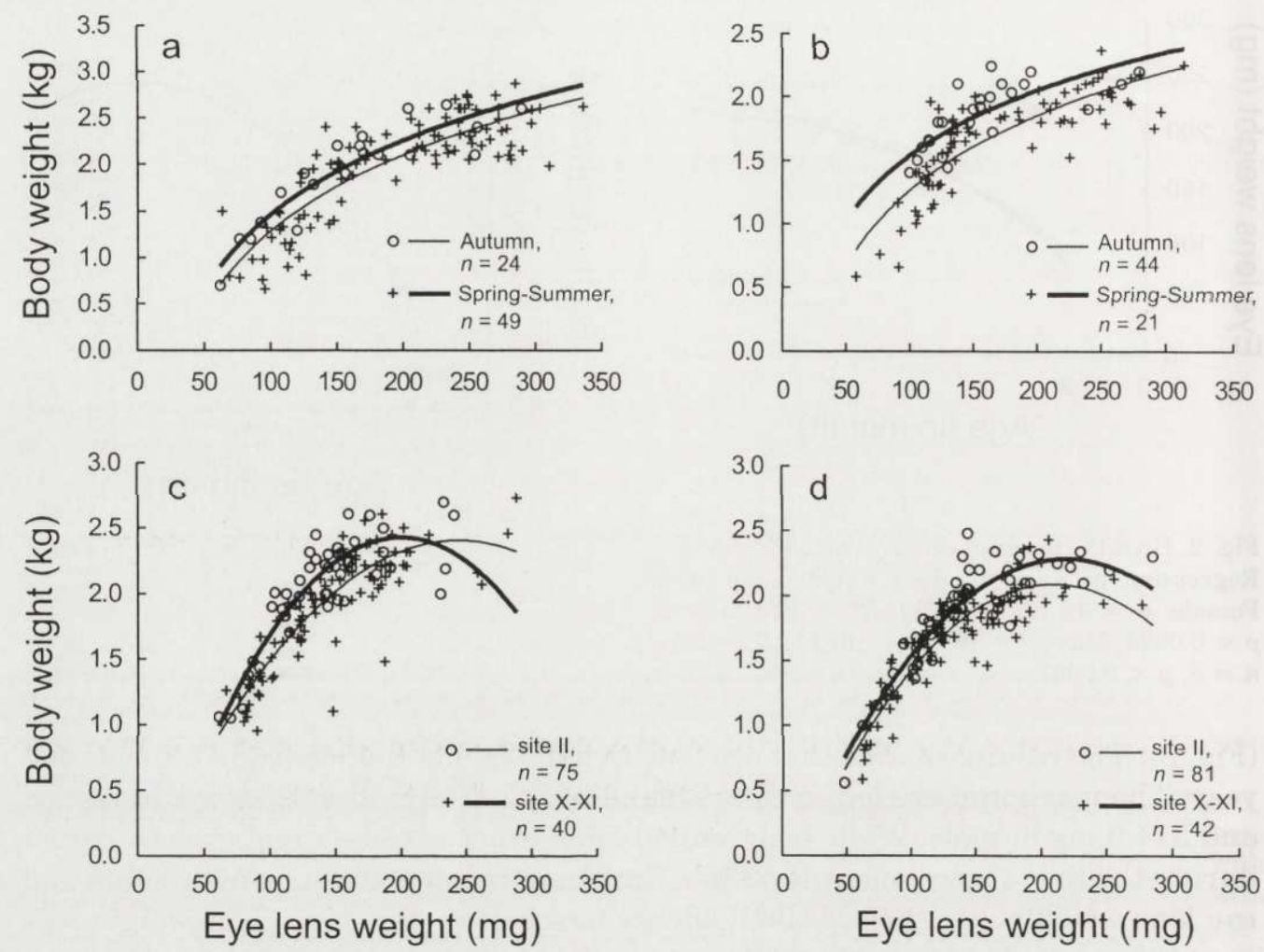

Fig. 4. Body weights in relation to eye lens weights of hares. Regression in juveniles with eye lens weights under $180 \mathrm{mg}$ : (a) Female in site III, Spring-Summer, $y=0.0134 x-0.1684\left(R^{2}=0.62\right.$, $p<0.0001)$; Autumn, $y=0.0122 x+0.1545\left(R^{2}=0.88, p<0.0001\right)$. (b) Male in site III, Spring-Summer, $y=0.0134 x-0.1925\left(R^{2}=0.70, p<0.0001\right)$; Autumn, $y=0.0081 x+0.6531\left(R^{2}=0.62\right.$, $p<0.0001)$. (c) Female in autumn, site II, $y=0.0110 x+0.3660\left(R^{2}=0.75, p<0.0001\right)$; site X-XI, $y=0.0123 x+0.4078\left(R^{2}=0.79, p<0.0001\right)$. (d) Male in autumn, site II, $y=0.0098 x+0.4167$ $\left(R^{2}=0.75, p<0.0001\right)$; site X-XI, $y=0.0101 x+0.4964\left(R^{2}=0.72, p<0.0001\right)$.

reproduction (see below), and 124.1-209.6 g in male (Fig. 4b, ANCOVA, $F_{1,57}=5.12$, $p<0.05)$. With the same eye lens weight $(100-180 \mathrm{mg})$, the juveniles from site II (average January temperature $-2^{\circ} \mathrm{C}$ ) in autumn (October-November) weighed less $191.8-275.8 \mathrm{~g}$ in female than those in site X-XI (average January temperatures $-13^{\circ} \mathrm{C}$ to $-9^{\circ} \mathrm{C}$ ), (Fig. $4 \mathrm{c}$, ANCOVA, $F_{1,112}=28.90, p<0.0001$ ) and $112.7-133.7 \mathrm{~g}$ in male (Fig. 4 d, ANCOVA, $F_{1,120}=12.17, p<0.001$ ).

Before attaining some body weight level $(1.5-2.2 \mathrm{~kg})$, the juveniles had spent more time at a site in spring-summer than in autumn, and in the southern region in autumn than in the northern, being 21-23 days in female and 7-48 days in male for the seasonal difference, 36-48 days in female and 33-36 days in male for the regional difference. 


\section{Body weight in relation to reproduction}

All the overwintering hares bred in February-September (Lu 1995). The overwintering hares $<1$ year (eye lenses of all specimens weighed over $180 \mathrm{mg}$ except for $170.6 \mathrm{mg}$ of a male specimen) was not significantly lighter than those $>1$ year in female (Table $2 ; t=1.73, p>0.05)$ and did not in male $(t=2.23, p<0.05$ ). The juveniles born in the current year were sexually matured at 3-4 months old, but only some $(51.7 \%)$ of the hares up to this age bred in July-September of the year (Lu 1995). The lightest eye lenses among all the breeding female juveniles were $142.3 \mathrm{mg}$ and the male $119.2 \mathrm{mg}$, which could be used as criteria of sexual maturity. For male juvenile there was no significant difference of body weights between the breeders and the non-breeders up to sexually-matured age (ANCOVA,

Table 2. Comparison of body weights (in $\mathrm{kg}$ ) of hares between different ages in site III during the breeding season (February-September) 1991. $n$-sample size.

\begin{tabular}{lllrrr}
\hline Age & & Sex & $n$ & Mean \pm SE & Range \\
\hline Overwintering hares & $<1$ year & Female & 12 & $2.24 \pm 0.06$ & $1.82-2.60$ \\
& & Male & 12 & $1.87 \pm 0.03$ & $1.60-2.05$ \\
& $>1$ year & Female & 41 & $2.38 \pm 0.04$ & $2.00-2.87$ \\
& & Male & 22 & $2.01 \pm 0.04$ & $1.52-2.37$ \\
Juveniles up to & \multirow{2}{*}{ Non-breeders } & Female & 8 & $1.79 \pm 0.01$ & $1.40-2.00$ \\
sexually-matured age & & Male & 19 & $1.66 \pm 0.05$ & $1.24-1.90$ \\
& \multirow{2}{*}{ Breeders } & Female & 10 & $2.13 \pm 0.06$ & $1.85-2.44$ \\
& & Male & 7 & $1.69 \pm 0.06$ & $1.50-2.00$ \\
\hline
\end{tabular}

$F_{1,22}=0.05, p>0.80$ ). The lightest breeding female juvenile was $1.85 \mathrm{~kg}$ and the male $1.50 \mathrm{~kg}$, compared with $1.82 \mathrm{~kg}$ of the overwintering female and $1.60 \mathrm{~kg}$ of the male. Because of relative short growth period, the mean body weight of the breeding male juveniles (average eye lens weight $=141.5 \mathrm{mg}$ ) was still significantly lighter than that of the overwintering $<1$ year (average eye lens weight $202.9 \mathrm{mg}$; $t=2.63, p<0.05$ ). For female, however, the breeding juveniles were heavier than the non-breeders up to sexually-matured age (ANCOVA, $F_{1,15}=4.02, p=0.06$ ), and near to the overwintering $<1$ year $(t=1.26, p>0.20)$, though the average eye lens weight of the former $(170.3 \mathrm{mg})$ was lighter than that of the latter $(203.8 \mathrm{mg})$. Therefore, the body weight of breeders was related to age and sex.

\section{Seasonal variation in body weights}

Body weight of the overwintering hares apparently varied with seasons (Fig. 5). Females were the lightest while males were the heaviest in the early breeding season, and then females became heavier while males lighter, but there were small peaks for both sexes in April. Male weight declined to its lowest point in July, and 


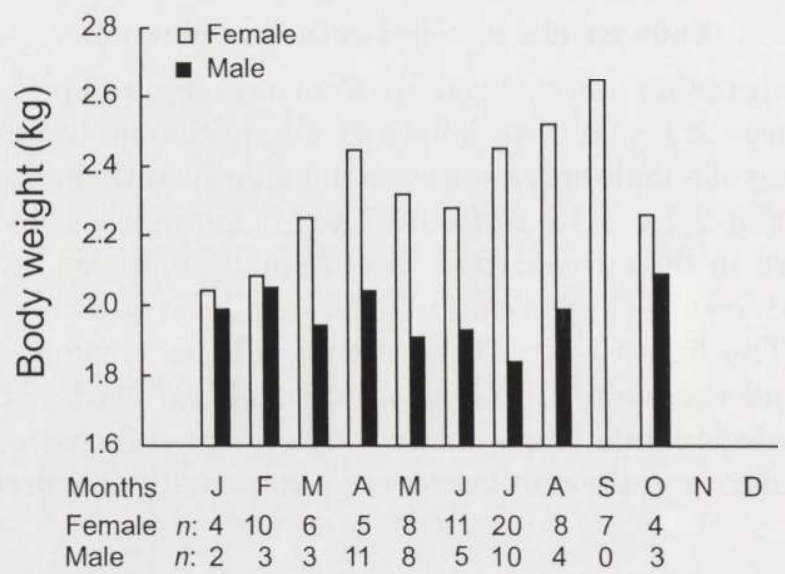

Fig. 5. Seasonal variation in mean body weight of the overwintering hares from site III. The numbers under the labels of $\mathrm{X}$ axis were monthly sample sizes.

the female reached its highest point in September. The heavier female body weights throughout the breeding season were related to increasingly accumulating of matter during the periods of pregnancy and nurture.

Body weights of game populations varied with the hunting seasons. The difference of mean weights of hares from mid-December $(1.9 \pm 0.02, n=275)$ to late-January $(1.95 \pm 0.02, n=70)$ in site II was not statistically significant $(t=0.24, p>0.70)$, correspondingly $2.10 \pm 0.05(n=38)$ and $2.00 \pm 0.04(n=86)$ in site III $(t=1.45, p>0.10)$. Therefore, the hunting season for the hares in the study region might be divided into two stages: (1) from early-October to early-December and (2) from late-December to late-January (Table 3). A difference of $0.09 \mathrm{~kg}$ between the mean body weights of the two stages was attributed to larger proportion of the incompletely-growing juveniles killed in the early stage.

\section{Sexual dimorphism in body weights}

Table 3 showed that females from all the investigated sites were significantly heavier than males both in early stage $(t=4.93, p<0.0001)$ and in late stage $(t=6.50, p<0.0001)$ of the hunting season. During the breeding season in site III, the dimorphism biased toward female were found in the overwintering hares $<1$ year $(t=5.24, p<0.0001$, Table 2$)$, those $>1$ year $(t=6.19, p<0.0001)$ and juvenile breeders $(t=4.75, p<0.0001)$, but did not in the non-breeding juveniles up to sexually-matured age $(t=1.35, p=0.19)$. ANCOVA showed that there were no significant sexual differences of body weights between the juveniles under sexually-matured age during the breeding season in site III $(1.26 \pm 0.07$, in 30 females; $1.17 \pm 0.08$, in 18 males; ANCOVA, $\mathrm{F}_{1,45}=0.18, p>0.65$ ), and between 
Table 3. Body weights (in $\mathrm{kg}$ ) of hares shot in the different stages of the hunting seasons from 12 sites. $n$ - sample size.

\begin{tabular}{|c|c|c|c|c|c|c|c|c|}
\hline \multirow{3}{*}{ Sites } & \multicolumn{4}{|c|}{ Early stage } & \multicolumn{4}{|c|}{ Late stage } \\
\hline & \multicolumn{2}{|c|}{ Female } & \multicolumn{2}{|c|}{ Male } & \multicolumn{2}{|c|}{ Female } & \multicolumn{2}{|c|}{ Male } \\
\hline & $n$ & Mean $\pm \mathrm{SE}$ & $n$ & Mean $\pm \mathrm{SE}$ & $n$ & Mean $\pm \mathrm{SE}$ & $n$ & Mean $\pm \mathrm{SE}$ \\
\hline I & 90 & $1.96 \pm 0.04$ & 55 & $1.85 \pm 0.03$ & & & & \\
\hline II & 154 & $1.85 \pm 0.03$ & 151 & $1.66 \pm 0.03$ & 283 & $1.99 \pm 0.02$ & 262 & $1.85 \pm 0.01$ \\
\hline III & 62 & $1.86 \pm 0.05$ & 56 & $1.77 \pm 0.04$ & 71 & $2.11 \pm 0.03$ & 53 & $1.93 \pm 0.05$ \\
\hline IV & 22 & $1.81 \pm 0.05$ & 20 & $1.70 \pm 0.06$ & & & & \\
\hline V & 53 & $1.98 \pm 0.06$ & 49 & $1.77 \pm 0.04$ & & & & \\
\hline VI & 56 & $1.95 \pm 0.05$ & 47 & $1.88 \pm 0.05$ & 47 & $2.00 \pm 0.04$ & 56 & $1.87 \pm 0.03$ \\
\hline VII & 66 & $2.04 \pm 0.04$ & 53 & $1.91 \pm 0.04$ & & & & \\
\hline VIII & & & & & 12 & $2.20 \pm 0.09$ & 10 & $1.91 \pm 0.06$ \\
\hline IX & & & & & 8 & $1.93 \pm 0.05$ & 8 & $1.95 \pm 0.03$ \\
\hline $\mathrm{X}$ & 17 & $2.02 \pm 0.08$ & 11 & $1.84 \pm 0.14$ & 7 & $2.23 \pm 0.07$ & 8 & $1.95 \pm 0.03$ \\
\hline XI & 22 & $1.98 \pm 0.10$ & 37 & $1.84 \pm 0.06$ & & & & \\
\hline XII & & & & & 14 & $2.16 \pm 0.08$ & 6 & $1.97 \pm 0.14$ \\
\hline Total & 542 & $1.92 \pm 0.02$ & 479 & $1.78 \pm 0.02$ & 442 & $2.02 \pm 0.02$ & 403 & $1.87 \pm 0.01$ \\
\hline
\end{tabular}

the juveniles with eye lens weight less than $180 \mathrm{mg}$ in autumn $(1.68 \pm 0.14$, in 24 females; $1.78 \pm 0.06$, in 21 males; ANCOVA, $\mathrm{F}_{1,38}=0.52, p>0.45$ ). However, in site II, the female juveniles with eye lens weight less than $180 \mathrm{mg}(1.79 \pm 0.05$, $n=75)$ in the hunting season were significantly heavier than the males $(1.60 \pm 0.04$, $n=81$ ) (ANCOVA, $\mathrm{F}_{1,153}=12.51, p<0.0005$ ). And the similar tendency also occurred between the juveniles in site X-XI $(1.99 \pm 0.06$, in 41 females; $1.81 \pm 0.06$, in 45 males; ANCOVA, $\mathrm{F}_{1,79}=18.39, p<0.0001$ ). Because of the limited specimens of older juveniles (eye lens weights over $180 \mathrm{mg}$ ) and adults in autumn-winter, the data of body weights from several sites were pooled. The results showed that after about 6 months old, the female juveniles $(2.22 \pm 0.03, n=36)$ significantly became heavier than the male $(2.09 \pm 0.04, n=29 ; t=2.74, p<0.01)$, even though there was no significant sexual difference of eye lens weights $(192.7 \pm 1.8$ in female and $193.8 \pm 2.3$ in male, $t=0.39, p>0.65)$. For adults, females $(2.36 \pm 0.06, n=18)$ also significantly weighed heavier than males $(2.12 \pm 0.05, n=11 ; t=2.97$, $p<0.01$ ) and similarly no significant difference of eye lens weights was found between both sexes $(259.7 \pm 5.1$ in female and $259.1 \pm 5.9$ in male; $t=0.08$, $p>0.90$ ). The maximum body weights of female and male collected in this study were $2.75 \mathrm{~kg}$ and $2.43 \mathrm{~kg}$ respectively. Therefore there was sexual dimorphism in body weights for the hare. 


\section{Discussions}

It is logically practicable to reestablish the growth process of hares in the field based on the data of the maximum/minimum eye lens weight and the breeding timing. The fact that eye lens weight keeps increasing with age during the first year of life (Broekhuizen and Maaskamp 1979, this study) supports the estimation method.

Although with the same eye lens weight the juvenile body weights in spring-summer weighed less than those in autumn, the growth rate of body weight (the slopes of regression equations in Fig. 4a, b) in the former was not lower than the latter correspondingly. Possibly during the earlier phase of life the growth rates of body weights of juveniles born in spring-later summer differed from those in late summer-early autumn.

Only some of juveniles, $10.6 \%$ for female and $10.5 \%$ for male, reached mean body weights of adult in the southern region in autumn, correspondingly $27.0 \%$ and $20.9 \%$ in the northern region, which could be partly attributed to the regional difference in growth rate of body weight (slopes of regression equations in Fig. $4 \mathrm{c}$, d). As a positive adaptation strategy to the colder environment, the juveniles in the northern region possibly intensively foraged in autumn and as a result their body weights gain faster. Menzies (1966) and Flux (1970) reported that, in the region near equator, juvenile $L$. capensis gained about $10 \mathrm{~g}$ in weight per day during the rapidly-growing period, reaching adult size at the 4 th or 5 th month of life. From Fig. 3, the growth rate during the first two months of life was estimated about $13 \mathrm{~g}$ per day. For other species of hares, the known daily growth rates include: $L$. europaeus, $19 \mathrm{~g}$ in New Zealand (Flux 1967), $28 \mathrm{~g}$ in Canada (Reynolds and Stinson 1959) and $29 \mathrm{~g}$ in Poland (Pielowski 1969); L. timidus, $14 \mathrm{~g}$ in Scotland (Hewson 1968, Flux 1970), $23 \mathrm{~g}$ in Norway (Walhovd 1965). It seems that the colder the region hare lives in, the faster the body weight grows.

According to Cabon-Raczyńska (1964) and Pepin (1979), a comparison of mean body weights between sites was made with the specimens of the same age. The juveniles (eye lens weights under $180 \mathrm{mg}$ ) from the northern region in the hunting season weighed significantly heavier than those from the southern region. However, for the older juveniles (eye lens weights over $180 \mathrm{mg}$ ) and adults, only male adults in the northern region was significant heavier than those in the southern $(t=2.81$, $p<0.05$, see Table 1$)$, and the others not $(t=0.38, p<0.70$ in female juveniles; $t=1.79, p=0.09$ in male juveniles; $t=0.08, p>0.90$ in female adults). With the limited data of adult body weights it was not suitable to test Bergmann rule, that the largest body of a given systematic group is found in the coldest climates because homeotherms must maintain a uniform internal temperature.

The pattern of seasonal variation of the hare body weight in this study was very similar to those of L. americanus (Newson 1964) and L. europaeus (Flux 1967). But other populations of $L$. americanus (Rowan and Keith 1959) and $L$. europaeus (Caboń-Raczyńska 1964) showed no seasonal fluctuations in adult body weights. 
Similar to the hare in this study, some hare populations such as L. californicus (Lechleitner 1959), L. americanus (Newson 1964), L. europaeus (Flux 1967, Caboń-Raczyńska 1974), and L. timidus (Flux 1970), have sexual dimorphism in body weight; but others, such as L. americanus (Rowan and Keith 1959) and L. europaeus (Caboń-Raczyńska 1964, Frylestam 1980) do not.

Acknowledgment: Dr J. E. C. Flux of Department of Scientific \& Industrial Research in New Zealand gave me encouragement to do the work. I am very grateful to my friends for their helps in collecting specimens, taking notes and analyzing data, and to Miss X. N. Jiang of University of Alabama in USA for her comment on English writing of the manuscript. The manuscript was greatly improved by comments from three anonymous reviewers and help from Prof Z. Pucek. The study was supported by the Foundation for Natural Sciences of Shanxi Province, P. R. China.

\section{References}

Agnew A. D. Q. and Flux J. E. C. 1970. Plant dispersal by hares (Lepus capensis L.) in Kenya. Ecology 51: 735-737.

Broekhuizen S. and Maaskamp F. 1979. Age determination in the European hare (Lepus europaeus Pallas) in the Netherlands. Zeitschrift für Säugetierkunde 44: 162-175.

Caboń-Raczyńska K. 1964. Studies on the European hare. II. Variations in the weight and dimensions of the body and the weight of certain internal organs. Acta Theriologica 9: 233-248.

Caboń-Raczyńska K. 1974. Variability of the body weight of European hares. Acta Theriologica 19: 69-80.

Chapman J. A. and Flux J. E. C. (eds) 1990. Rabbits, Hares and Pikas. Status Survey and Conservation Action Plan. IUCN, Gland: 1-68.

Flux J. E. C. 1967. Reproduction and body weight of the hare Lepus europaeus Pallas, in New Zealand. New Zealand Journal of Science 10: 357-401.

Flux J. E. C. 1970. Life history of the mountain hare (Lepus timidus scoticus) in northeast Scotland. Journal of Zoology, London 161: 75-123.

Flux J. E. C. and Jarvis J. U. M. 1970. Growth rates of two African hares, Lepus capensis. Journal of Mammalogy 51: 798-799.

Friend M. and Severinghaus C. W. 1967. Influence of nutrition of eye-lens weight in deer. New York Fish and Game Journal 14: 166-175.

Frylestam B. 1980. Growth and body weight of European hares (Lepus europaeus) in the southern Sweden. Holarctic Ecology 3: 81-86.

Hewson R. 1968. Weights and growth rates in the mountain hare Lepus timidus scoticus. Journal of Zoology, London 154: 249-262.

Lechleitner R. R. 1959. Sex-ratio, age classes and reproduction of the Black-tailed Jack rabbit. Journal of Mammalogy 40: 63-81

Lu X. 1995. Studies on breeding biology of the Cape hare (Lepus capensis). Acta Theriologica Sinica 15: 122-127. [In Chinese with English summary]

Lu X., Shen S. Y. and Gao S. W. 1994. Determination of age and analysis of population structure in the Cape hare (Lepus capensis). Acta Theriologica Sinica 14: 176-183. [In Chinese with English summary]

Lu X., Shen S. Y. and Gao S. W. 1995 Some ecological aspects of the Cape hare (Lepus capensis) in Shanxi province China. Chinese Journal of Zoology 30: 50-53. [In: Chinese with English summary]

Menzies J. I. 1966. A note on the diet and growth rate of hand-reared African hares, Lepus capensis. International Zoo Yearbook 6: 72 .

Newson J. 1964. Reproduction and prenatal mortality of Snowshoe hares on Manitoulin Island, Ontario. Canadian Journal of Zoology 42: 987-1005.

Pielowski Z. 1969. Sex ratio and weight of hares in Poland. Acta Theriologica 14: 119-131. 
Pepin D. 1979. Body weight of hare in the Paris basin (France). [In: Proceeding of the World Lagomorph Conference. K. Myers and C. D. MacInnes, eds]. Guelph University Press, Guelph: 229-238.

Reynolds J. K. and Stinson R. H. 1959. Reproduction in the European hare in the southern Ontario. Canadian Journal of Zoology 37: 627-631.

Rowan W. and Keith L. B. 1959. Monthly weights of Snowshoe hares from north central Alberta. Journal of Mammalogy 40: 221-226.

Stewart D. R. M. 1971. Diet of Lepus capensis and L. crawshayi. Journal of East Africa Wildlife 9: 161-162.

Walhovd H. 1965. Age criteria of the mountain hare (Lepus timidus L.) with analyses of age and sex ratios, body weights and growth in some Norwegian populations. Meddelelser fra Statens Viltundersokelser 2: 1-57.

Received 9 June 1998, accepted 11 August 1999. 